Heleodório Honorato dos Santos

\title{
Abordagem Clínica e Psicossocial das Lesões por Esforços Repetitivos LER / DORT
}

\author{
Clinical and Psycho-Social \\ Perspective of Repetitive Strain \\ Injuries RSI / WRMD
}

Professor do Departamento de Fisioterapia e Mestrando em Engenharia de Produção da Universidade Federal da Paraíba
Revisão bibliográfica, com abordagem clínica, psicológica e social dos problemas causados pelas Lesões por Esforços Repetitivos - LER, hoje melhor definidas como Distúrbio Osteomusculares Relacionados ao Trabalho - DORT. São discutidos neste texto, a sinonímia utilizada em toda a literatura pesquisada, alguns dados epidemiológicos, em nível mundial e nacional, quanto à distribuição da doença segundo algumas varáveis tais como: sexo, idade, tipo de atividade, tempo e localização anatômica das queixas, afastamento do trabalho etc. Além desses pontos, são enfocados estudos sobre fatores etiológicos e fisiopatológicos das LER / DORT. Por fim, buscou-se uma correlação entre todos estes fatores anteriormente citados e o psicossocial, pontuando os elementos que influenciam diretamente no aparecimento e/ ou manutenção desta enfermidade multifatorial, salientado a importância da organização do trabalho na sua prevenção.

Palavras-chaves Lesões por Esforços Repetitivos, Doença Ocupacional, Distúrbios Osteomusculares Relacionados ao Trabalho.

This is a bibliographical revision work involving clinical, psychological and social disorders that are caused by the commonly known repetitive strain injuries (RSI) and better defined nowadays as Work-Related Musculo-skeletal Disease (WRMD). The synonymy used throughout the researched literature is discussed in this text, together with some national and worldlevel epidemiological data concerning the distribution of the disease, listed in relation to some variables, such as: sex, age, type of activity, duration and location of anatomical complaints, absence from work, etc. Besides the above, studies were focused on the etiological and physiopathological factors of RSI / WRMD, furthermore, efforts were made to establish a correlation between the aforementioned factors and psycho-social factors, pointing out the elements that directly influence the manifestation and / or maintenance of this multi-factorial infirmity, and the importance that work organization has in relation to its prevention.

Keywords Repetitive Strain Injuries (RSI), Occupational Disease, Work-Related Musculo-skeletal Disease (WRMD). 


\section{Definição e nomenclatura}

Conforme HELFENSTEIN JR. (1998), existe uma verdadeira confusão entre os diversos profissionais, no que se refere ao conceito e terminologia sobre o assunto, fazendose necessária uma uniformização destes, para que sejam evidenciadas várias questões no âmbito dos relatórios médicos e nas decisões terapêuticas e judiciárias.

A taxonomia (ciência das classificações) tem apresentado confrontos, não só na semântica, como também, nas implicações científicas, para os profissionais da área da saúde, desde os tempos de Hipócrates.

Ao pé da letra, a terminologia LER, implica na afirmação de uma lesão tecidual, o que não acontece na maioria dos casos, como também sustenta a tese de que a mesma foi causada por repetição de movimentos, deixando de lado outras formas de cargas biomecânicas, a exemplo das atividades onde se desenvolva sobrecarga muscular estática para manutenção da postura por períodos prolongados, tarefas executadas em força máxima, situações de trabalho realizados em altas temperaturas, ou ainda tarefas com instrumentos vibratórios.

Já, segundo BARREIRA (1994), as LER são definidas como um conjunto de disfunções músculo-esqueléticas que acometem os membros superiores e região cervical, estando relacionadas ao trabalho principalmente em áreas como indústria de eletro-eletrônicos, de alimentos, químicas, têxteis, serviços de telefonia e de entrada de dados em terminais de computação, entre outras.

Dados os motivos anteriormente citados na literatura, nos deparamos com uma série de nomenclaturas destinadas a nomear essa condição patológica:

- distúrbios ou desordens por trauma cumulativo;

- síndrome do esforço repetitivo;

- distúrbios músculo-esqueléticos ocupacionais;

- síndrome ombro-braço;

- síndrome do membro superior;

- síndrome cervicobraquial ocupacional;

- síndrome da hipersolicitação;

- síndrome da dor crônica do membro superior;
- injúrias por uso repetitivo;

- lesões de sobrecarga ocupacional;

- injúrias ocupacionais de esforço de repetição;

- distúrbios do membro superior relacionados ao trabalho.

O mais novo termo usado para substituir a LER, é a DORT (Distúrbios Ósteo-musculares Relacionados ao Trabalho), ao nosso ver, muito mais adequado, pois, agrupa nele vários outros estados dolorosos que não possuem, imperativamente, lesão tecidual, muito embora não seja o ideal, pois exclui os distúrbios ligamentares e as neuropatias periféricas, sendo, a julgamento do autor, os termos, Distúrbios Ocupacionais do Aparelho Locomotor ou Distúrbios reumáticos Ocupacionais (ou Relacionados ao Traba(ho), os mais adequados.

Apesar de terem sido desenvolvidos mais de 2000 estudos a respeito da LER ou DORT, vários autores (BARTON, 1989 e 1992; VENDER et al, 1995; WEILAND, 1996; HADLER, 1997) concordam que nenhum desses estudos conseguiv estabelecer um nexo causal, pois não puderam relacionar, anatomicamente, os sinais e sintomas apresentados com as atividades ocupacionais específicas.

Geralmente, se considera como LER apenas as enfermidades da coluna cervical, cintura escapular e membro superior, onde destacam as doenças tendíneas inflamatórias (tendinite da cabeça longa do bíceps e do supra-espinhoso, epicondilite medial e lateral, tenossinovites do punho e as tenossinovites extenosantes); as neuropatias compressivas, particularmente a síndrome do túnel do carpo; a síndrome tensional do pescoço e os cistos sinoviais, com tendência a se excluir os demais segmentos do corpo, pois as enfermidades músculo-esqueléticas, principalmente as relacionadas ao trabalho, se desenvolvem em menor número nos membros inferiores (MMII).

No Brasil, as ações judiciais trabalhistas associadas aos MMII, correspondem a menos de $10 \%$ do total de ações relacionadas aos distúrbios músculo-esqueléticos na maioria dos países industrializados.

HELFENSTEIN JR. (1999), adverte que devemos considerar LER ou DORT, qualquer distúrbio que seja relacionado ao trabalho, 
independente do segmento afetado, pois desta forma, podemos envolver também as lombalgias, bursite isquiática, neuralgia parestésica, bursite infrapatelar, tendinite calcanear, fasciite plantar, dentre outros.

\section{Dados epidemiológicos}

Devido ao seu surgimento e crescimento rápidos, AWERBUCH (1985), afirmou que: "a LER não é viral mas é bastante virulenta".

O grande número de terminologias e de conceitos atribuídos a ela, refletem numa dificuldade na aquisição de dados confiáveis para o estudo da incidência e prevalência dos diferentes tipos de distúrbios músculoesqueléticos relacionados ao trabalho.

No mundo todo, a LER/DORT vem aumentando, substancialmente, em locais como a Nova Zelândia, Escandinávia, Austrália, Canadá e principalmente os EUA, onde se- gundo ZETTERBERG (1997), as doenças do sistema músculo-esquelético apresentam uma incidência anual de 14\%, entre todos os atendimentos médicos, abrindo destaque para dor lombar que equivale a $48 \%$ de todas as injúrias ocupacionais que ocasionam perda de trabalho, tendo causado enorme prejuízo àquele país pelos afastamentos e indenizações decorrentes.

Cá entre nós, no Brasil, somente a partir de 1987, foi que a LER ficou reconhecida como doença ocupacional, e portanto, como doença ocupacional indenizável, sendo este um dos grandes motivos de nossa estatística, a respeito, não retratar fielmente o quadro existente, é o que nos afirma OLIVEIRA (1991). Para se ter uma idéia da situação, o quadro abaixo refere-se aos registros, apenas em Belo Horizonte, realizados pelo grupo pericial de acidente do trabalho do Instituto Nacional de Seguridade Social (INSS).

Quadro I Prevalência de LER /DORT no INSS de Belo Horizonte.

\begin{tabular}{c|c|c}
\hline ANO & TOTAL DE CASOS & PREVALÊNCIA \\
\hline 1985 & 01 & $1,56 \%$ \\
\hline 1986 & 03 & $4,55 \%$ \\
\hline 1987 & 95 & $40,95 \%$ \\
\hline 1988 & 132 & 41,77 \\
\hline
\end{tabular}

Fonte: Lesões por Esforços Repetitivos: conceitos básicos (Helfenstein Jr., 1999)

Basta ver que, em apenas 2 anos as LER/ DORT passaram de $1,56 \%$ para $40,95 \%$ de prevalência, ou seja, a ascensão das "doenças profissionais" registradas naquela cidade, aconteceu de maneira arrebatadora, ressaltando que as mulheres foram responsáveis por $76 \%$ dos casos. Já em São Paulo, segundo os dados da Secretaria de Saúde do Estado, foram diagnosticados como LER/ DORT, cerca de 20.000 casos entre 1985 e 1992.

Infelizmente, somente em alguns estados, a exemplo de São Paulo, é que se pode obter informações regionalizadas sobre o tema. $\mathrm{Na}$ região metropolitana existe o CEREST (Centro de Referência de Saúde do Trabalhador do Estado de São Paulo), com atuação em várias áreas da região. O outro é o Centro de Referência do Trabalhador, que é mantido pela Prefeitura de São Paulo, e também é dividido por regiões.

Conforme CODO \& ALMEIDA (1995), no primeiro programa vamos encontrar dados epidemiológicos referentes a 620 pacientes distribuídos segundo as variáveis abaixo:

1 - distribuição da LER segundo o sexo;

2 - distribuição da LER segundo a faixa etária;

3 - distribuição da LER segundo o ramo de atividade;

4 - distribuição da LER segundo antecedentes de trabalho com movimentos repetitivos; 
5 - distribuição da LER segundo o local das queixas;

6 - distribuição da LER segundo o tempo das queixas (meses);

7 - distribuição da LER segundo os meses de afastamento; $\mathrm{e}$

8 - distribuição da LER segundo a função.

Num outro estudo realizado por TESHIMA \& FONSECA (1994), no Centro de Referência da Prefeitura de São Paulo, foi verificado que $93,1 \%$ dos 318 pacientes atendidos tinham entre 20 e 49 anos de idade e que as profissões mais afetadas eram: auxiliar de produção industrial $(24,5 \%)$, digitador $(17,6 \%)$, operador de caixa $(9,4 \%)$,montador $(6,0 \%)$, operador de máquinas industriais $(3,8 \%)$, telefonista $(3,5 \%)$, costureira $(3,1 \%)$, compensador (1,9\%), empregada doméstica $(1,3 \%)$ e outras $(25,1 \%)$, sendo que as regiões do corpo mais atingidas eram o punho e mão com $98,8 \%$ e ombro e cotovelo com $31 \%$.

\section{Etiologia}

Na realidade, os estudiosos das LER/DORT acreditam que a causa ou fator etiológico atribuído a este conjunto de afecções ainda é desconhecida, pois vários pesquisadores do assunto a nível mundial (BOUVIER, 1982; HOCKING, 1987 e HALES \& BERTSCHE, 1992), citados por HELFENSTEIN Jr. (1999), têm mostrado que não existe relação entre a repetição do movimento e a incidência da doença.

Sabe-se que, o indivíduo treinado e fisicamente condicionado, que se porta corretamente durante a jornada de trabalho, descansando a intervalos regulares, realiza, sem prejuízo algum, as suas tarefas. Em nosso país, os auxiliares de montagem, bancários e digitadores, são os trabalhadores que mais apresentam diagnóstico de LER/DORT, referindo dor e desconforto na coluna cervical e nos membros superiores (MMSS), porém, a patologia de maior incidência entre eles é a tenossinovite de punho (do extensor comum dos dedos e do extensor radial do carpo), conforme FERRAZ (1995) e LIMA \& SIQUEIRA (1999). Resumidamente, os fato- res etiológicos que dizem respeito às LER/ DORT podem ser elencados como:

1) desrespeito aos fatores ergonômicos e antropométricos (equipamentos, acessórios, ferramentas, mobiliários, posicionamentos, angulações, distâncias, etc);

2) excesso de jornadas;

3) ausência de intervalos apropriados;

4) técnicas incorretas;

5) posturas indevidas;

6) força excessiva na execução de tarefas;

7) sobrecarga estática; e

8) sobrecarga dinâmica.

\section{Fisiopatologia}

Conforme a resolução SS-197 de 08/06/ 1992 da Secretaria da Saúde do Estado de são Paulo, as LER têm origem ocupacional decorrentes de formas combinadas ou não, de: res;

1 - uso repetitivo de grupos muscula-

2 - uso forçado de grupos musculares;

e das.

3 - manutenção de posturas inadequa-

BAUMMER \& MARTIN (1988), mostram que em virtude do desconhecimento de muitos aspectos patológicos inerentes às LER, como também em função dos fortes componentes psicossociais e econômicos que norteiam o tema, surgiram duas correntes que tentam fazer valer suas opiniões. De um lado, encontram-se os que defendem que a dor e a disfunção causadas pela LER, são consequentes de lesões orgânicas nos tecidos relacionados às tarefas desempenhadas no trabalho, enquanto que um outro grupo de estudiosos afirma que as LER representam situações de neurose compensatória, conversão, fadiga ou simplesmente simulação.

As estruturas anatômicas envolvidas na fisiopatologia das LER, encontram-se no interior das articulações (ligamentos, sinóvias, cápsulas) ou em área adjacente (tendões, músculos, fáscias e nervos). Os tendões e os ligamentos têm como função principal modular a transmissão de forças para que não haja uma concentração de cargas entre os vários componentes do sistema músculo- 
esquelético. Identicamente, a outros sistemas do corpo, as propriedades físicas e químicas dos tendões e ligamentos, variam com diversos fatores, como a idade, o sexo, a temperatura, a presença de fatores hormonais, atividades, etc.

KANNUS \& JOZSA (1991), afirmaram que as lesões degenerativas nos tendões, podem surgir na população, em geral acima de 35 anos de idade, quando a reposição do tecido tendíneo já não é tão eficaz, tanto no que diz respeito à velocidade quanto à qualidade, e que as alterações na estrutura física dos tendões e na microvascularização podem receber influências hormonais, bioquímicas, imunológicas e mecânicas. Esta faixa etária é a que mais sofre com a doença, e é também a idade mais produtiva das pessoas. Este estudo sugere ainda que ela se instala, progressivamente, o que demonstra chance de reversão do quadro quando medidas adequadas forem tomadas em tempo hábil.

Os tendões sofrem stress tensional e compressivo, ocasionados, respectivamente, pelos músculos, ossos e ligamentos, respondendo aos mesmos através de deformidades nas matrizes dos tecidos, ou ainda, por alterações fisiológicas, que se dão, provavelmente, pela obstrução do fluxo sanguíneo e com isto cessando o aporte nutricional. Evidentemente, o grau de apresentação dessas alterações depende da intensidade, da duração e da frequência de extensão do tendão.

No trabalho citado acima, os autores observaram que em $62 \%$ dos tendões rompidos, a vascularização estava presente, porém os vasos apresentavam diminuição do lúmem devido à hipertrofia das camadas íntima e média de suas paredes. Estas mesmas alterações foram, também, encontradas em $2 / 3$ do grupo controle, que apesar de serem considerados normais no exame macroscópico, a microscopia mostrou que os mesmos eram anormais.

Segundo NICOLETTI (1997), quando as LER se instalam, a capacidade natural de reparação dos tecidos que a pessoa possui já foi ultrapassada, ou os mecanismos de controle imunológico que regulam a regeneração dos tecidos gastos sofreram modificações. Os componentes estruturais dos tecidos são substituídos de maneira inadequa- da, sobrevindo cicatrizes, mudanças das propriedades mecânicas, e provavelmente, $a$ inflamação em tendões, nervos, fáscias e cápsula articular

Os fenômenos inflamatórios têm intensidade muito variável e são auto-alimentados pela interação entre as alterações biológicas e mecânicas dos tecidos envolvidos e acomodações do sistema nervoso, na direção da manutenção da homeostase vital.

Ele afirma não dispor de dados seguros para considerar a LER como sendo devido "apenas" à consequência de interações entre as pessoas, geneticamente programadas para, serem "deprimidas ou histéricas" e condições de trabalho desfavoráveis. É possível que os distúrbios emocionais sejam o espetho comportamental de modificações biológicas desencadeadas pelas agressões sofridas.

Apesar da discordância entre os autores sobre a relação do trabalho com as patologias ocupacionais, algumas delas são mais evidentes, a exemplo das epicondilites, que segundo ALLENDER (1974), num estudo envolvendo 15.000 pessoas, foi ela a que se mostrou ter a maior incidência na população geral. Nas tendinites de ombro, nos trabalhadores industriais, existe uma certa controvérsia entre a ocorrência deste tipo de patologia com relação ao trabalho leve e pesado, foi a conclusão a que chegaram alguns trabalhadores.

Com relação às neuropatias periféricas, os investigadores elegeram a síndrome do túnel do carpo como a de maior incidência, apregoando como fatores causais: o excesso de força, a alta repetitividade, uso de instrumentos vibratórios e posturas inapropriadas. Fatores estes que chegam a aumentar em 10 vezes (de 3 para $30 \mathrm{mmHg}$ ) a pressão dentro do túnel carpal, que por sua vez, provocará lesão no nervo mediano.

Em 1988, NATHAN et al. investigaram mais de 400 trabalhadores, de 4 indústrias americanas e chegaram a conclusão que, antes de tudo, existe uma pré-disposição constitucional, pois dos 27 tipos de ocupações diferentes, desempenhadas com as mãos, neste estudo, não identificaram nenhuma correlação entre esta neuropatia periférica e a atividade manual.

SIEGEL et al. apud HELFENSTEIN JR. 
(1999), reafirmam a hipótese das variações congênitas encontradas (duplicações de fáscias e de músculos, lateralização dos tendões, diminuição da velocidade de condução nervosa) traz uma importante contribuição para etiopatogenia da síndrome do túnel do carpo.

No que diz respeito aos distúrbios ocupacionais que atingem a região cervicobraquial, a mialgia tensional cervical (síndrome tensional do pescoço) é a síndrome miofacial mais observada na prática médica. Segundo KUORINKA (1979), ela é característica de indivíduos que executam tarefas em posturas estáticas com rotação ou flexão sustentadas do pescoço, ou ainda, trabalhos prolongados e repetitivos que adotem abdução ou extensão dos MMSS. Na Finlândia, ela corresponde a $60 \%$ do total das LER/ DORT, enquanto que na Escandinávia, representa $40 \%$.

Vários autores dizem ser a isquemia o principal fator da fisiopatologia das L.ER/DORT. Já outros, a exemplo de MCKINNOM \& NOVAK (1994), associam as posturas inadequadas e os movimentos impróprios à sua patogênese, afirmando que determinadas posições podem: 1) resultar no aumento direto da compressão nervosa; 2) causar contratura muscular, e secundariamente, compressão de estruturas neuromusculares; e 3) estabelecer um desequilíbrio muscular.

\section{O FENÔMENO NO BRASIL}

Segundo LIMA \& SIQUEIRA (1999), o trajeto oficial da doença no Brasil foi registrado, a partir de 1987, quando o Ministério da Previdência Social reconheceu a doença como de origem ocupacional, porém, com algumas restrições quanto a sua denominação, tendo em 1993, aprovado a denominação de "lesões por esforços repetitivos".

O número de pessoas com diagnóstico de LER/DORT tem aumentado, substancialmente, nos últimos anos, deixando como resultado: um grande número de dias de trabalho perdidos; queda da produtividade; geração de grandes somas pagas em indenizações; surgimento de conflitos internos na empresa; um impacto importante na economia do país; e um significante fenômeno social.
Na realidade, pelo amplo raio de patologias que as LER/DORT pode alcançar, gera uma corrida incessante à estimativa de diagnósticos, que pelas afirmações de HELFENSTEIN JR. (1999), chega-se ao ponto de se tachar de "tenossinovites" dores em tendões desprovidos de bainha sinovial. Também, a artrite reumatóide e o lúpus eritematoso sistêmico (LES), são exemplos de patologias diagnosticadas como LER/DORT.

Ele diz que, no Brasil, os principais motivos de tal epidemia, são os seguintes:

01) falta de organização no ambiente de trabalho;

02) insatisfação com o trabalho;

03) despreparo dos médicos e outros profissionais envolvidos;

04) exames complementares sem confiabilidade;

05) influência dos sindicatos;

06) ações políticas;

07) oportunismo de advogados;

08) influência da mídia;

09) disposição ética, moral e intelectual dos indivíduos;

10) tensão social da época;

11) interesse pela compensação financeira ou pela aposentadoria precoce; e

12) um sistema trabalhista permissivo.

É imperativo dizer que, para o surgimento deste fenômeno, tantos os fatores sociais, quanto os psicológicos, se revestem de uma grande importância, visto que a percepção da dor pode ser distorcida pela ansiedade ou depressão, pela expectativa de uma lesão e pelos interesses da indenização.

Vários estudos apontam para o fato de que os esquemas compensatórios influenciam na perpetuação de síndromes dolorosas crônicas, no aparecimento de doenças pasicossomáticas e de lesões de sintomatologia persistente.

Ainda conforme HELFENSTEIN JR. (1999), "a LER/DORT se tornou, no Brasil, uma exuberante iatrogenia social".

\section{Abordagem psicossocial da LER}

Por ser a LER consideradsa, segundo 
ARAÚJO (1998), como uma patologia multideterminada é que vários estudiosos da áreas da saúde, da gestão da produção, da psicopatologia do trabalho, da ergonomia, etc, que estão voltados para a pesquisa, têm trabalhado na busca da prevenção e tratamento dela, através de um atendimento multidisciplinar.

Fazendo parte deste contexto, a psicossociologia tem lugar de destaque no tratamento preventivo e/ou curativo desta patologia, pois é considerada uma disciplina sem fronteiras, já que seu conteúdo teórico é formado no conjunto de ciências tais como: antropologia, história, psicanálise, sociologia, psicologia, etc, visando a complexidade da problemática do trabalho.

O autor, anteriormente citado, entende que, não se compreendem a produção de conhecimento e as práticas de prevenção, sem a participação concreta dos trabalhadores, vistos como sujeitos indispensáveis, na construção coletiva da análise da LER, assim como, na elaboração de propostas de mudanças organizacionais, visando à prevenção da patologia. O mesmo se aplica a todo trabalho psicoterapêutico ou socioterapêutico com os lesionados, pois cabe-lhes aí ocupar o lugar de sujeito na tarefa de compreensão do adoecimento, bem como, na formulação de novas estratégias coletivas e individuais, para enfrentar a condição de portadores da LER, para dar um novo sentido à história pessoal, nela incorporando a doença.

A abordagem psicossocial da LER é compartilhada pela grande maioria dos pesquisadores que afirmam ser ela uma patologia multifatorial e que segundo PAGÉS apud ARAÚJO (1998), tem a competência e a originalidade de levar em conta os processos heterogêneos, tradicionalmente estudados de maneira separada, negando a hipótese de causa única no surgimento da LER.

Através da multidisciplinalidade é que se mergulha numa relação dialética entre as diversas teorias, permitindo a cada pesquisador, criticar e questionar conceitos dos outros, ao mesmo tempo que interpela sua própria disciplina e o conjunto de pensamento da equipe, além do que, ajuda a reescrever seus próprios postulados, colocando-o numa posição de aprendizagem contínua. Ao mes- mo tempo em que os diversos saberes são partilhados, renuncia-se a qualquer forma imperialista de pensar.

Obviamente, a psicossociologia nega a abordagem mecanicista que visualiza uma doença profissional como a LER, como um simples desajuste ergonômico entre o homem e seus equipamentos de trabalho, de fácil reparo. Ela, de uma maneira holística, esboça o dia-a-dia dos trabalhadores, dentro e fora do local de trabalho, ou seja, vai além das tarefas executadas, da organização e das condições de trabalho, pois acredita que a dor presente em cada sujeito acometido de LER, tem sua origem, também, nas relações entre a vida profissional e a vida privada, no salário, no plano de carreira, nas expectativas de relação profissional e pessoal.

Ainda segundo ARAÚJO (1998), o sofrimento das tarefas deve ser entendido como algo que antecede e sucede à materialização do gesto laboral, e não apenas, o imediatismo de sua execução. Para a maioria dos pacientes, afirma NICOLETTI (1997), as LER continuam sendo fonte de dor e sofrimento, de angústia e de medo sobre o presente e sobre o futuro de sua capacidade de ganhar o seu salário.

DEJOURS (1993), nos afirma que o indivíduo se percebe como parte de uma complexa rede que diz respeito à representação de si mesmo e da posição social que ocupa, enquanto trabalhador e cidadão. Diz ele que enquanto trabalhador, cada indivíduo se empenha, consciente ou inconscientemente, em apaziguar os conflitos entre a sua imagem "narcísica" e os atributos sociais positivos ou negativos de sua identidade profissional. É dessa forma que cada atitude sua, cada tarefa executada, se incorporam num universo conflitante, onde as utopias e a realidade se debatem continuamente.

A dimensão do sofrimento se inicia nestes conflitos, do ponto de vista existencial, o que certamente, vai além do "mal-estar" associado a uma patologia específica como a LER Na maioria das vezes, esse "mal-estar" percebido pelo trabalhador, gera um sofrimento que vai além de seu corpo biológico, tendo uma dimensão que atinge o universo simbólico, em que o sujeito está inserido. Esse sofrimento não se deixa conhecer ou explicitar, embora o trabalhador o vivencie. A verdade é que ele está presente em seu 
cotidiano, mas não mostra nitidamente a sua cara e nem se deixa nomear de maneira clara. Alguns sociólogos e psicólogos acreditam que as LER sejam a manifestação somática de algumas angústias do nosso tempo, uma espécie de histeria coletiva desencadeada pela organização do trabalho moderno, em pessoas com perfil emocional susceptível.

Para GASPARINI apud RODRIGUES (1992), a LER deve ser percebida como sendo um produto das interações que ocorrem entre o ser humano e seu ambiente, frequentemente hostil, entre condições pessoais, físicas e psíquicas predisponentes e a sua exposição a um ambiente facilitador, que contribui para gerar doenças físicas e mentais. Além do que, os profissionais que lidam com a LER devem: conhecer o melhor que puderem da fisiologia e biomecânica do aparelho locomotor; ter noções de ergonomia para que entendam os fatores de riscos aos quais o paciente se expõe durante as tarefas; empregar métodos reprodutíveis de avaliação funcional e registro das ocorrências, de maneira a possibilitar controles epidemiológicas e avaliação de resultados de tratamentos eficazes; conhecer os locais onde existem recursos adequados para sua recuperação e orientá-los no sentido de procurá-los; e por fim, precisam conhecer as consequências sofridas por um trabalhador que desenvolve LER, seus direitos e as dificuldades que ele encontrará quando for introduzido no sistema da saúde previdenciário ou privado.

$\mathrm{Na}$ realidade, as lesões por esforços repetitivos são reais e não ocorrem apenas nos trabalhadores de fábricas, indústrias, bancos, etc. Elas acometem também atletas de elite, músicos, bailarinos e até donas de casa que, apesar de não estarem submetidas às condições peculiares da organização moderna do trabalho, apresentam queixas e sinais clínicos semelhantes às doenças ocupacionais dos trabalhadores das linhas de montagem.

\section{A importância de um exa- me médico acurado no diagnóstico e prevenção}

Um médico que vai atender a um paciente proletário não se deve limitar a por a mão no pulso, com pressa, assim que che- gar, sem se informar das suas condições. Não delibere, de pé, sobre o que the convém ou não convém fazer, como se não lidasse com a vida humana.

É perceptível, pelas palavras de Ramazzini, um médico italiano, que já estudava as doenças ocupacionais, cerca de 200 anos atrás, antes mesmo da revolução industrial e dos métodos taylorista/fordista de organização da produção que, mesmo naquela época, a atenção à saúde do trabalhador já deixava a desejar, mesmo não existindo INSS e SUS. Apesar de terem passados tantos anos, elas parecem atuais e fazem levar a classe médica (principalmente ortopedistas e médicos do trabalho) além de todos os profissionais aliados no atendimento as doenças ocupacionais, a uma reflexão profunda de seu papel perante a sociedade. É fundamental que seja realizado um exame ortopédico acurado, com enfoque em capacidade funcional do apareIho locomotor, para execução de tarefas específicas, pois um dos papéis importantes que o exame médico ocupacional tem é de possibilitar a diminuição das chances de uma pessoa que não apresente os atributos físicos necessários para a execução de um determinado trabalho venha a ser exposta aos riscos inerentes da atividade que a tornará doente.

Não podemos ignorar que muitos dos postos de trabalho atuais, exigem, para a execução das tarefas a que se destina, capacidade física não encontrável em todas as pessoas medianamente dotadas de resistência aos esforços estáticos, às más posturas causadas por uma cadeira ou layout de fábrica inadequados. Geralmente, o trabalhador não conta com um programa de prevenção e de condicionamento físico, aumentando suas chances de ficar doente. O pior é que, ao ser acometido da lesão, ele, na maioria das vezes, não contará com o auxílio de um atendimento médico eficaz, em virtude da situação em que se encontram, hoje, os serviços encarregados de atendê-lo.

\section{A organização do traba- lho e a prevenção das LER}

Não é de hoje que as patologias ocupacionais se apresentam em nosso meio. Ramazzini, em um dos seus escritos, dizia: a 
natureza impõe ao gênero humano a necessidade de prover a vida diária através do trabalho. Dessa necessidade surgiram todas as artes, como as mecânicas e as liberais, que não são desprovidas de perigos, como aliás, todas as coisas humanas. $E$ forçoso confessar que ocasionam muitos danos aos artesãos, certos ofícios que eles desempenham. Onde esperavam obter recursos para sua própria manutenção e da família, encontram graves doenças e passam a amaldiçoar a arte à qual se haviam dedicado.

As doenças do sistema músculo-esquelético associadas ao trabalho, aparecem num percentual mais acentuado nos grandes conglomerados urbanos, muito embora não deixem de ocorrer também em locais onde não foram impostos os métodos de organização do trabalho.

Pela afirmação de ROCHA et al. (1993), é preciso que os profissionais de saúde, os empresários e o Estado, avaliem o papel que lhes cabe na prevenção e no tratamento das doenças ocupacionais do aparelho locomotor.

COUTO (1996), opina que, a adequação dos postos de trabalho às pessoas que neles operam aos princípios ergonômicos, a adoção de métodos de administração que valorizem o aspecto humano das pessoas que trabalham na empresa e a disposição de todas as partes envolvidas no trabalho, de envidar esforços para encontrar respostas adequadas para o problema das LER, são o melhor caminho que temos para seguir e o único que realmente tem chances de interromper 0 tremendo desperdício de recursos financeiros e de saúde pública que as doenças ocupacionais do aparelho locomotor têm provocado.

Conforme CODO (1995), os fatores de riscos na organização do trabalho responsáveis pelas LER, estão ligados ao sistema taylorista/fordista (ritmo de trabalho, alta repetitividade, conteúdo das tarefas e a qualidade da comunicação) associado a uma proposta contrária ao mesmo, ou seja, a incompatibilidade de se associar força de trabalho às novas tecnologias que necessitam da presença ativa do cérebro, gerando uma assincronia.

As LER, segundo ele, são um sintoma desta dessincronia entre a exigência de um trabaIho plenipotenciário, com uma organização fragmentada do trabalho.

Sem dúvida nenhuma, a LER é uma doença, mas do ponto de vista da organização do trabalho, ela é um sintoma, e talvez, por esquecerem disso, é que algumas empresas se deparam com verdadeiras epidemias, pois para evitar que ela se alastre, tentam tratar, isoladamente, cada caso no maior sigilo possível. Ao contrário, o aparecimento da LER, em seus momentos iniciais, torna-se uma aliada da gerência, no sentido de detectar as falhas na organização do trabalho e eliminar os fatores que as promovem. A abertura de canais de comunicação entre a gerência e trabalhadores, visando esclarecimentos e acolhimento das queixas surgidas após os turnos de trabalho, é um fator importante na prevenção da LER, afetando de forma menos contundente, a produtividade do setor, pois só conhecendo determinada patologia é que podemos combatê-la e preveni-la.

Para o autor acima mencionado, o primeiro e principal ponto num programa de prevenção da LER, é um diagnóstico organizacional completo, que se divide em duas partes: um diagnóstico das condições de saúde mental do trabalhador. No que se refere ao primeiro, qualquer forma de diagnóstico clássico da organização do trabalho serve para detectar os pontos críticos desencadeantes da LER. $O$ segundo, mais recente, é baseado num protocolo com 228 questões fechadas, cujo tempo médio de resposta é de 40 minutos, em aplicação coletiva, que foi elaborado nos últimos 10 anos na Universidade de São Paulo, sobre saúde e trabalho, constando das seguintes partes:

- um inventário clássico de personalidade e psicopatologia (versão 168, resumida, do MMPI);

- uma escala de stress individual e no trabalho (baseada nas escalas norteamericanas);

- uma escala de carga mental no trabalho;

- uma escala de suporte social afetivo e suporte social institucional;

- uma escala de análise das relações sociais na produção, subdividida entre relações pares e relações hie- 
rárquicas;

- uma escala de participação nos processos decisórios); e

- uma escala de satisfação no trabalho.

Alerta o autor, que o método, sumariamente descrito, procura como qualquer diagnóstico, a melhoria das condições de trabalho em busca de maior produtividade e bem estar do trabalhador. Para que isto aconteça, é

\section{Referências Bibliográficas}

ALLENDER, E. Prevalence, incidence and remission rates of some common rheumatic diseases and syndromes. Scand J. Rhematol 3: 145-153; 1974

AWERBUCH, M. RSI: or "Kangaroo Paw". Med. J. Aust. 142: 237-238; 1985.

ARAÚJO, José Newton Garcia de. Abordagem Psicossocial da LER. In: LER - dimensões ergonômicas e psicossociais. Belo Horizonte: Health, 1998.

BAMMER, G. \& MARTIN, B. The arguments about RSI: an examination. Community Health studies XII (3): 348-355, 1988.

BARREIRA, T. H. C. Fatores de risco de lesões por esforços repetitivos em uma atividade manual. Dissertação de mestrado. Instituto de Psicologia da USP, 1994.

BARTON, N. J. Repetitive strain disorder: often misdiagnosed and often not work related. BMJ 299: 405-406; 1989.

BARTON, N. J. et al. Occupational causes of disorders in the upper limb. BMJ 304: 309-311; 1992.

CODO, Wanderley. Apresentação. In: LER - diagnóstico, tratamento e prevenção. Petrópolis: Vozes, 1995. $335 p$. necessário que: os sindicalistas instituam em sua pauta, políticas intervencionistas nas condições de trabalho; que os empresários vejam as reivindicações dos trabalhadores como algo coadjuvante no aumento da produtividade; e que os administradores percebam que o trabalho é algo mais que o emprego, não sendo avaliado pela tarefa em si, e sim, pelo significado do gesto laborativo.

COUTO, H. A. Ergonomia aplicada ao trabalho. Belo Horizonte: Ergo, 1996.

DEJOURS, C. De la peine au travail. Revista Autrement, no 142, fev. 93, p 138151.

FERRAZ, M. B. et al. Upper-extremity musculoskeletal disorders in keiboard operators in Brazil: a cross-sectional study. Int. J. Occup. Environ Health 1: 239-244; 1995.

HADLER, N. M. Repetitive upper extremity motions in the workplace are not hazardous. J Hand Surg 22 A: 19-29; 1997.

HELFENSTEIN JÚNIOR, Milton. Lesões por esforços repetitivos (LER/DORT): conceitos básicos. São Paulo: Schering-Ploug, 1999.

KANNUS, P. \& JOZSA, L. Histopathological changes precending spontaneous rupture of a tendon: a controled study of 891 patients. J Bone Jt Surg 73 A: 1507-1525; 1991.

KUORINKA, I. \& KOSKINEN, P. Occupational rheumatic diseases and upper limb strain in manual jobs in a light mechanical industry. Scand. J. Work Environ Health. 5 : 39-47; 1979. 
LIMA, S. M. P. F. \& SIQUEIRA, M. A. Terapia ocupacional na reabilitação industrial e as lesões por esforços repetitivos / distúrbios osteomusculares relacionados ao trabalho (LER/ DORT). Reabilitar 5:33-36, 1999.

McKINNON, S.E. \&NOVAK, C. B. Clinical commentary: pathogenesis of cumulative trauma disorders. J. Hand Surg. 19 A : 873-883; 1994

NATHAN, P. A.; MEADOWS, K. D. \& DOYLE, L. S. Occupation as a risk factor for impaired sensory conduction of the median nerve at the carpal tunnel. J. Hand Surg. 13 B: 167-170; 1988.

NICOLETTI, Sérgio. Lesões por esforços repetitivos (LER): leitura técnica continuada de LER. São Paulo: BristolMyers Squibb Brasil, 1997.

OLIVEIRA, C. R. Lesões por esforços repetitivos (LER). Ver. Bras. Saúde Ocup 19: 59-85; 1991.

RAMAZZINI, B. As doenças dos trabalhadores. São Paulo: Fundacentro, 1992. 180p.
ROCHA, L. E.; RIGOTTO, R. M. \& SILVESTRE, M. P. Lesões por esforço repetitivo: um problema da sociedade brasileira. In: LER diagnóstico, tratamento e prevenção. Petrópolis: Vozes, 1995. P 321-325.

RODRIGUES, A. L. Estresse e trabalho. Proteção. 17 (4): 90-94, 1992.

TESHIMA, G. \& FONSECA, S. M. P. Incidência de LER segundo o tipo de atividade. Rio de Janeiro: Congresso Brasileiro de Reabilitação da Mão, 1994.

VENDER, M. I. et al. Upper extremity disorders: a literature review to determine work-relatedness. J Hand Surg 20 A:534-541; 1995.

WEILAND, A. J. Repetitive strain injuries and cumulative trauma disorders. J Hand Surg 21 A: 337; 1996.

ZETTERBERG, C. Epedemiology of the lower extremity. In: musculoskeletal disorders in the workplace - principles and pratice. Mosby-Year Book: 481- 485; 1997. 